\title{
Influence of polyvinyl alcohol fiber and fly ash content on compressive creep properties of high ductility cementitious composites
}

\author{
Bo Chen ${ }^{1 *}$, Liping Guo ${ }^{2}$, Lihui Zhang ${ }^{2}$, Wenxiao Zhang ${ }^{1}$, Yin Bai ${ }^{1}$ and Xiongfeng Wang ${ }^{1}$ \\ ${ }^{1}$ State Key Laboratory of Hydrology-Water Resources and Hydraulic Engineering, Nanjing Hydraulic Research Institute, Nanjing ,210029, \\ China \\ ${ }^{2}$ Collaborative Innovation Center for Advanced Civil Engineering Materials, Southeast University, Nanjing ,211189, China
}

\begin{abstract}
The influence of polyvinyl alcohol (PVA) fiber volume fraction and fly ash content on the creep behavior of high ductility cementitious composites (HDCC) under compression was investigated. For this investigation, the creep behavior of four HDCC groups with cube compressive strength of 30-50 MPa, PVA fiber volume fraction of $1.5 \%$ and $2.0 \%$, and fly ash content of $60 \%$ and $80 \%$ at $7 \mathrm{~d}$ and $28 \mathrm{~d}$ loading periods, respectively, were evaluated. A compressive creep model, which reflects the loading age and holding time, was established. The results revealed that when the load was applied at $7 \mathrm{~d}$ and $28 \mathrm{~d}$, and then maintained for $245 \mathrm{~d}$, the specific creep of HDCC ranged from $95 \times 10^{-6} / \mathrm{MPa}$ to $165 \times 10^{-6} / \mathrm{MPa}$ and from $59 \times 10^{-6} / \mathrm{MPa}$ to $135 \times 10^{-6} / \mathrm{MPa}$, respectively. The corresponding creep coefficients ranged from 1.48 to 2.25 and from 1.10 to 1.94 , respectively. The PVA fiber volume fraction and fly ash content were the main factors affecting the specific creep of HDCC, which increased with increasing fiber fraction and fly ash content. Under short-term loading, the fiber volume fraction played a leading role in the specific creep, and the fly ash content played the leading role during long-term loading. Furthermore, the specific creep and creep coefficient decreased significantly with increasing loading age. The classical creep model described by a power exponent function is suitable for HDCC.
\end{abstract}

\section{Introduction}

Concrete creep refers to an increase in deformation of concrete with time under a long-term constant load. Creep will lead to the elimination of stress concentration from the concrete structure, lead to a uniform stress redistribution, and reduce the temperature stress of concrete. Moreover, the creep will increase the deflection of flexural members by 2-3 times, increase the additional eccentricity of slender columns, and lead to a prestress loss of prestressed members. To avoid the detrimental consequences of creep, a deep understanding of concrete creep properties is essential. High ductility cementitious composites (HDCC) is a kind of fiber-reinforced cementbased composites, which are based on the theory of micromechanics and fracture mechanics, and have been systematically designed to exhibit high ductility under tensile and shear loads. ${ }^{[1]}$ Furthermore, HDCC differ significantly from the ordinary concrete in raw materials, which are mainly reflected in the fact that: the maximum aggregate size of HDCC is only $1.18 \mathrm{~mm}$ or less, coarse aggregates are absent, while the maximum fine aggregate size of ordinary concrete is $5 \mathrm{~mm}$, and the coarse aggregate size ranges from $5 \mathrm{~mm}$ to $31.5 \mathrm{~mm}$ or greater; the maximum volume content of the PVA fiber in HDCC ranges from $2.0 \%$ to $3.0 \%$ or greater, which is significantly higher than the $0.1 \%$ fiber volume content of ordinary concrete; the maximum fly ash content of HDCC is $40 \%$ to $80 \%$, which is considerably higher than the $10 \%$ to $30 \%$ content typical of ordinary concrete. Boshoff and Benny et al ${ }^{[2-4]}$ proposed that the bending and tensile creep behavior of HDCC differs significantly from that of ordinary concrete and ordinary fiber concrete due to the multi-cracking characteristics of HDCC and the bond slip of high content fiber. $\mathrm{He}$ and $\mathrm{Yu}{ }^{[5,6]}$ proposed that a high PVA fiber content would increase the creep coefficient of concrete. Rouse ${ }^{[7]}$ reported that the creep deformation of HDCC was larger than that of ordinary concrete, but ACI and CEB-FIP models could be used to predict the creep deformation of HDCC. Clarification regarding whether the creep behavior of HDCC differs significantly from that of ordinary concrete, and whether the classical concrete specific creep time history model is suitable for HDCC is required.

The creep model with an Abel clay pot was used by $\mathrm{Li}^{[8]}$ and Zhang ${ }^{[9]}$ to describe the creep characteristics of HDCC. The model and the process of determining parameters are quite complex. Wang et al. ${ }^{[10]}$ established a three-stage polynomial creep model and a two-stage hyperbolic function creep model. In addition, Sun ${ }^{[11]}$ and

*Corresponding author's e-mail :bchen@nhri.cn 
Wang ${ }^{[12]}$ et al. established a Nelder hyperbolic power function creep model. These models consider only the load duration as the variable, and neglect the effect of loading age. At present, most creep models of HDCC only provide the creep expression associated with a given loading age, i.e., different parameters of the expression are needed for different loading ages. A HDCC model that includes both the loading age and loading duration is lacking. A creep model is used to calculate the creep deformation associated with different ages and duration, and is suitable for finite element stress analysis and convenient for application.

In this work, four groups of HDCC with compressive strength of 30-50 MPa, fiber volume content of $1.5 \%$ and $2.0 \%$, and fly ash content of $60 \%$ and $80 \%$ are systematically investigated. This investigation is used to determine the time history relationship of the specific creep and creep coefficient under loading ages of $7 \mathrm{~d}$ and $28 \mathrm{~d}$. Moreover, a compression creep degree model, which accurately reflects the loading age and loading duration, is established.

\section{Materials and methods}

\subsection{Materials}

The cement was P-II 42.5R (Nanjing Conch Cement Co., Ltd.) with performance that meets the requirements of P.II 42.5R in GB 175-2007 Common Portland Cement. The fly ash was grade I class F (low calcium) fly ash (Nanjing Thermal Power Plant) with fineness, water demand ratio, and loss on ignition of $4.6 \%, 92 \%$, and $3.1 \%$, respectively. Furthermore, the fine aggregate was ordinary river sand with a maximum particle size of $1.18 \mathrm{~mm}$, fineness modulus of 1.0, and mud content of 0 . The water reducing agent was polycarboxylic acid high performance water reducing agent (Sika Company), with solid content of $40 \%$ and water reducing rate of more than $40 \%$. The test water was ordinary tap water.

The physical and mechanical properties of the polyvinyl alcohol (PVA) fiber (Yongan Baohualin Co., Ltd.) are shown in Table 1.

\begin{tabular}{cccccc} 
Table1. & \multicolumn{5}{c}{ Physical and mechanical properties of PVA fiber } \\
\hline $\begin{array}{c}\text { Ultimat } \\
\text { e tensile } \\
\begin{array}{c}\text { strength } \\
/ \mathrm{MPa}\end{array}\end{array}$ & $\begin{array}{c}\text { Elastic } \\
\mathrm{s} / \mathrm{GPa}\end{array}$ & $\begin{array}{c}\text { Ultimate } \\
\text { elongatio } \\
\mathrm{n} / \%\end{array}$ & $\begin{array}{c}\text { Equivalen } \\
\text { t diameter } \\
/ \mu \mathrm{m}\end{array}$ & $\begin{array}{c}\text { Lengt } \\
\mathrm{h} / \mathrm{mm}\end{array}$ & $\begin{array}{c}\text { Density } \\
/\left(\mathrm{g} / \mathrm{cm}^{3}\right. \\
)\end{array}$ \\
\hline$\geq 1300$ & $>35$ & $6 \sim 8$ & $30 \sim 40$ & 12 & 1.3 \\
\hline
\end{tabular}

\subsection{Mix proportions of HDCC}

The water to binder ratio (W/B) of HDCC was 0.25 , the aggregate to binder ratio (A/B) was 0.363 , the fly ash content was $60 \%$ and $80 \%$, and the fiber volume content was $1.5 \%$ and $2.0 \%$. Based on the requirement that the plastic viscosity of fresh paste should lie within $1 \mathrm{~Pa} \cdot \mathrm{s}-8$ $\mathrm{Pa} \cdot \mathrm{s}^{[13]}$, a water reducer dosage of $1.20 \%-2.80 \%$ was employed. The mix proportion parameters of HDCCs are shown in Table 2.
Table2. Mix proportion parameters of $\mathrm{HDCCs}^{\mathrm{a}, \mathrm{b}}$

\begin{tabular}{|c|c|c|c|c|c|c|}
\hline \multirow{2}{*}{$\begin{array}{l}\text { Mix } \\
\text { No. }\end{array}$} & \multirow{2}{*}{$\mathrm{W} / \mathrm{B}$} & \multicolumn{2}{|c|}{ B } & \multirow{2}{*}{$\mathrm{A} / \mathrm{B}$} & \multirow{2}{*}{$\begin{array}{l}\mathrm{V}_{\mathrm{f}} \\
/ \%\end{array}$} & \multirow{2}{*}{$\begin{array}{c}\mathrm{WR} / \mathrm{C} \\
/ \%\end{array}$} \\
\hline & & $\mathrm{C}$ & $\mathrm{F}$ & & & \\
\hline V2F8 & 0.25 & 1 & 4.0 & 0.363 & 2.0 & 2.80 \\
\hline V15F8 & 0.25 & 1 & 4.0 & 0.363 & 1.5 & 2.00 \\
\hline V2F6 & 0.25 & 1 & 1.5 & 0.363 & 2.0 & 1.60 \\
\hline V15F6 & 0.25 & 1 & 1.5 & 0.363 & 1.5 & 1.20 \\
\hline
\end{tabular}

code meaning: C-cement, F-fly ash, B-cementitious material $(\mathrm{B}=\mathrm{C}+\mathrm{F})$, A-fine river sand aggregate, $\mathrm{W}$ water, $V_{f}$-volume content of PVA fiber, WR- water reducer.

b The percentage of superplasticizer is calculated based on the mass of cement.

\subsection{Test methods}

HDCC mechanical-property test. In accordance with the GB/T 17671-1999 "Method of testing cementsDetermination of strength," the flexural and compression tests were performed, and $40 \mathrm{~mm} \times 40 \mathrm{~mm} \times 160 \mathrm{~mm}$ prism specimens were tested.

A HDCC creep test was performed in accordance with the relevant provisions of the "compression creep test" section outlined in GB/T 50082-2009 "Standard for test methods of long-term performance and durability of ordinary concrete." The test was performed on $100 \mathrm{~mm} \times$ $100 \mathrm{~mm} \times 400 \mathrm{~mm}$ prism specimens, and the corresponding prism compressive specimens and shrinkage specimens were fabricated. The loading ages are $7 \mathrm{~d}$ and $28 \mathrm{~d}$, and the loading stress of the creep test is $40 \%$ of the compressive strength of the prism. Two HDCC specimens in each group were stacked, and the deformation test was conducted using a dial indicator. Two dial indicators were placed on each specimen. The deformation test device of the shrinkage specimen was the same as that employed for the creep test.

\section{Results and discussion}

\subsection{HDCC mechanical properties}

A water to binder ratio (W/B) of 0.25 is employed for the four HDCC groups, but the volume content of PVA fiber $(1.5 \%$ and $2.0 \%)$ and the content of fly ash $(60 \%$ and $80 \%)$ are varied. The flexural strength and compressive strength of HDCC cured for $28 \mathrm{~d}$ are shown in Table 3.

Table3. Mechanical properties of HDCCs for standard curing 28 days

\begin{tabular}{cccccc}
\hline Mix & $\begin{array}{c}\text { Flexural } \\
\text { strength } \\
\text { No. }\end{array}$ & $\begin{array}{c}\text { Compressive } \\
\text { strength } \\
/ \mathrm{MPa}\end{array}$ & $\begin{array}{c}\text { Ratio of } \\
\text { flexural } \\
\text { strength to } \\
\text { compressive } \\
\text { strength }\end{array}$ & $\begin{array}{c}\mathrm{V}_{\mathrm{f}} \\
/ \%\end{array}$ & $\mathrm{FA} / \%$ \\
\hline V2F8 & 16.3 & 34.1 & 0.48 & 2.0 & 80 \\
V15F8 & 14.8 & 35.0 & 0.42 & 1.5 & 80 \\
V2F6 & 21.4 & 43.8 & 0.49 & 2.0 & 60 \\
V15F6 & 16.5 & 51.9 & 0.32 & 1.5 & 60 \\
\hline
\end{tabular}

For a given PVA fiber volume content, the mechanical properties of HDCC improve with decreasing fly ash content; for a fiber content of $1.5 \%$, the ratio of the 
flexural strength to the compressive strength increases with increasing ash content. The ash content has little effect on when the fiber content is $2.0 \%$. For a given fly ash content, the compressive strength of HDCC increases with decreasing PVA fiber volume content, whereas the ratio of the flexural strength to the compressive strength decreases. The effect of the fiber content on this ratio is more significant than that of the ash content.

\subsection{HDCC creep property}

\subsubsection{Loading stress of creep test.}

The prism compressive strength test results of HDCC at 7 $\mathrm{d}$ and $28 \mathrm{~d}$ are shown in Table 4. A stress ratio of 0.4 is employed for the creep test. The compressive strength data (see Table 3 and Table 4) are compared. This comparison reveals that the influence of the PVA fiber and fly ash content on the compressive strength of the prism specimen is almost consistent with that of the cube specimen.

Table4. Compressive strength of prism specimen and creep stress of $\mathrm{HDCCs}^{\mathrm{c}}$

\begin{tabular}{|c|c|c|c|c|c|c|}
\hline \multirow[t]{2}{*}{$\begin{array}{l}\text { Mix } \\
\text { No. }\end{array}$} & \multicolumn{2}{|c|}{$\begin{array}{c}\text { Compressive } \\
\text { strength of } \\
\text { prism specimen } \\
/ \mathrm{MPa}\end{array}$} & \multicolumn{2}{|c|}{$\begin{array}{l}\text { Loading stress of } \\
\text { creep test } / \mathrm{MPa}\end{array}$} & \multirow[t]{2}{*}{$\begin{array}{l}\mathrm{V}_{\mathrm{f}} \\
/ \%\end{array}$} & \multirow[t]{2}{*}{$\begin{array}{l}\text { FA } \\
/ \%\end{array}$} \\
\hline & $7 d$ & $28 \mathrm{~d}$ & $\begin{array}{c}\text { Loading } \\
\text { at } 7 \mathrm{~d}\end{array}$ & $\begin{array}{l}\text { Loading } \\
\text { at } 28 \mathrm{~d}\end{array}$ & & \\
\hline V2F8 & 14.2 & 20.6 & 5.7 & 8.2 & 2.0 & 80 \\
\hline V15F8 & 16.2 & 25.5 & 6.5 & 10.2 & 1.5 & 80 \\
\hline V2F6 & 24.6 & 36.7 & 9.8 & 14.7 & 2.0 & 60 \\
\hline V15F6 & 26.8 & 39.2 & 10.7 & 15.7 & 1.5 & 60 \\
\hline
\end{tabular}

$\mathrm{c}$ the size of prism specimen is $100 \mathrm{~mm} \times 100 \mathrm{~mm} \times 400$ $\mathrm{mm}$.

3.2.2 HDCC specific creep. The specific creep of four HDCC groups loaded on $7 \mathrm{~d}$ and $28 \mathrm{~d}$ is investigated. The loads are applied according to the creep stress shown in Table 4 (duration of creep test: $245 \mathrm{~d}$ ). The specific creep versus the loading duration curves are shown in Fig 1 and Fig 2.

Specific creep refers to the creep deformation of concrete under unit stress. When four groups of HDCC (V2F8, V15F8, V2F6, and V15F6) are loaded at $7 \mathrm{~d}$, the specific creep at a loading duration of $245 \mathrm{~d}$ is $165 \times$ $10^{-6} / \mathrm{MPa}, 145 \times 10^{-6} / \mathrm{MPa}, 140 \times 10^{-6} / \mathrm{MPa}$, and $95 \times$ $10^{-6} / \mathrm{MPa}$, respectively. For loading at $28 \mathrm{~d}$ under the same loading duration, the creep values $\left(135 \times 10^{-6} / \mathrm{MPa}, 99 \times\right.$ $10^{-6} / \mathrm{MPa}, 85 \times 10^{-6} / \mathrm{MPa}$, and $\left.59 \times 10^{-6} / \mathrm{MPa}\right)$ are $18 \%$, $31 \%, 39 \%$, and $38 \%$ lower, respectively, than those obtained for loading at $7 \mathrm{~d}$.

Fig 1 and Fig 2 indicate that the content of PVA fiber and fly ash has considerable influence on HDCC creep, i.e., the specific creep increases with increasing content of fiber and fly ash. For loading at $7 \mathrm{~d}$, the specific creep of V2F8 with the highest content of both fiber and fly ash develops the fastest and and the creep is the largest. The specifi creep of V15F6 with the lowest content of both fiber and fly ash is the lowest. Furthermore, the difference between the maximum and minimum values, $70 \times$
$10^{-6} / \mathrm{MPa}$, is $27 \%$ of the average of the two values.

The specific creep of V2F6 with a PVA fiber content of $2 \%$ and fly ash content of $60 \%$ is higher than that of V15F8 with a fiber content of $1.5 \%$ and ash content of $80 \%$ at an early stage. The specific creep of V15F8 exceeds that of V2F6 at a loading duration of $90 \mathrm{~d}$. However, the specific creep difference between these materials at a loading duration of $245 \mathrm{~d}$ is only $5 \times 10^{-6} / \mathrm{MPa}$, accounting for $3.5 \%$ of the average value of the two creep levels. In the early stage, the specifice creep of HDCC with high PVA fiber content and low fly ash content is slightly higher than that of HDCC with low fiber content and high fly ash content. The influence of fiber content on specific creep in this stage is more significant than that of the fly ash. The hydration time increases with increasing fly ash content. In the long age, the content of fly ash plays a leading role in the development trend of specific creep. Therefore, the effect of fly ash content on the specific creep of HDCC increases with increasing loading duration.

The specific creep of four HDCC groups loaded at 28 $\mathrm{d}$ exhibits the same trend as that of HDCCs loaded at $7 \mathrm{~d}$, but the difference between the groups increases. The largest specific creep and the smallest specific creep occur for V2F8 and V15F6, respectively; the specific creep of $\mathrm{V} 15 \mathrm{~F} 8$ starts to exceed that of V2F6 at a loading duration of $120 \mathrm{~d}$.

The severity of the HDCC creep-property changes increases with increasing loading age. The ratios of the specific creep difference between the other groups and V2F8 to the specific creep of V2F8 at a loading duration of $245 \mathrm{~d}$ are calculated. For loading at $7 \mathrm{~d}$, the ratios of V15F8, V2F6, V15F6 to V2F8 are $12 \%, 15 \%$, and $43 \%$, respectively, and are $27 \%, 37 \%$, and $56 \%$, respectively, for loading at $28 \mathrm{~d}$. The influence of fly ash content on the specific creep of HDCC becomes increasingly important due to the delay of loading age.

This indicates that the content of PVA fiber and fly ash are the main factors affecting the specific creep of HDCC, which increases with increasing content of PVA fiber and fly ash. Under short-term load, the fiber content plays a leading role in specific creep, while under long-term load, the fly ash content plays the leading role.

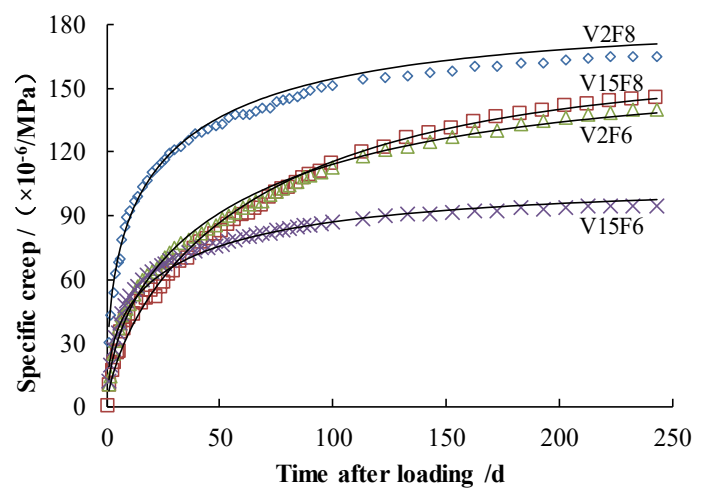

Figure 1. Measured value and fitting curve of HDCCs specific creep with loading at age of $7 \mathrm{~d}$ 


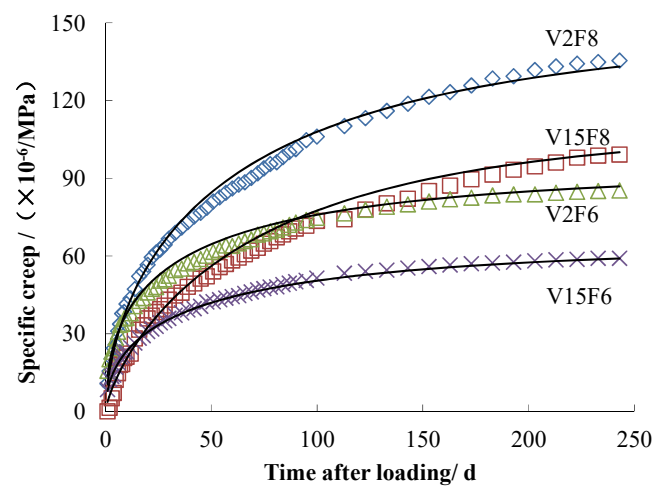

Figure 2. Measured values and fitting curve of HDCC specific creep with loading at age of $28 \mathrm{~d}$

3.2.3 HDCC specific creep model. The specific creep of concrete $\mathrm{C}(\mathrm{t}, \tau)$ is related to the loading age and the loading duration $\mathrm{t}-\tau$. The specific creep model can effectively reflect the specific creep value of HDCC under different loading ages and different loading duration, and meet the needs of structural design analysis and finite element calculation. Moreover, the creep function is commonly expressed using (among others) a power function, logarithmic function, hyperbolic function, exponential function, exponential sum, power exponential function, and polynomial exponential function. In this work, to express the relationship between specific creep and loading age and loading duration, the specific creep of HDCC based on the classical concrete specific creep model proposed by $\mathrm{Zhu}^{[14]}$ is evaluated.The power exponent function of specific creep is as follows:

$$
C(t, \tau)=\left(\phi_{0}+\phi_{1} \tau^{-p}\right)\left[1-e^{-\left(r_{0}+r_{1} \tau^{-q}\right)(t-\tau)^{(a+b \ln (\tau))}}\right]
$$

Where: $C(\mathrm{t}, \tau)$-specific creep, $\times 10^{-6} / \mathrm{MPa} ; \tau$-loading age, $\mathrm{d} ; \mathrm{t}-\tau$-loading duration, $\mathrm{d} ; \phi_{0}, \phi_{1}, r_{0}, r_{1}, p, q, a, b-$ constant.

By calculating and analyzing the specific creep data of HDCC $^{[15]}$, the test constants of Formula 1 are obtained (see Table 5). The fitting curves drawn based on these constants and Table 5 are shown as the solid lines in Fig 1 and Fig 2. The fitting correlation coefficient is high and the deviation between the fitting value and the measured value is $\leq 5 \%$. Therefore, the classical concrete creep model is suitable for HDCC.

Table5. Test constants of creep model for HDCCs

\begin{tabular}{cccccccccc}
\hline HDCCs mix No. & $\phi_{0}$ & $\phi_{1}$ & $r_{0}$ & $r_{1}$ & $p$ & $q$ & $a$ & $b$ & $\mathrm{R}^{2}$ \\
\hline V2F8 & 3.00 & 237.03 & 0.05 & 3.44 & 0.15 & 1.5 & 0.18 & 0.13 & 0.9968 \\
V15F8 & 3.00 & 268.86 & 0.02 & 0.07 & 0.28 & 0.49 & 0.61 & 0.05 & 0.9985 \\
V2F6 & 3.00 & 316.12 & 0.01 & 0.13 & 0.38 & 0.10 & 0.42 & 0.06 & 0.9923 \\
V15F6 & 3.00 & 210.72 & 0.05 & 0.36 & 0.35 & 0.45 & 0.39 & 0.04 & 0.9978 \\
\hline
\end{tabular}

\subsubsection{HDCC creep coefficient.}

The creep coefficient, which is the ratio of the creep strain to the elastic strain at initial loading, is obtained for four groups of HDCC (V2F8, V15F8, V2F6, and V15F6), as shown in Fig. 3 and Fig. 4. The time-history curve of the creep coefficient is similar to that of the specific creep. However, the coefficient differs significantly among the four groups for loading at an age of $7 \mathrm{~d}$. For loading at 28 d, except for the V2F8 group, the creep coefficient of the other three HDCC groups increases gradually with increasing holding time. The coefficients of HDCC with load duration of $245 \mathrm{~d}$ are $2.25,1.88,2.03$, and 1.48 (difference between highest and lowest values: 0.77), respectively, when loaded at $7 \mathrm{~d}$. When loaded at $28 \mathrm{~d}$, the creep coefficients are 1.94, 1.18, 1.25, and 1.10, respectively (difference between highest and lowest values: 0.84 ), and the difference between the coefficients of different groups increases. The coefficient of V2F8, V15F8, V2F6, and V15F6 decreased by 14\%, 37\%, 38\%, and $26 \%$, respectively, when the loading age is increased from 7 days to 28 days. Therefore, the mix proportion and material composition of HDCC have considerable influence on the creep coefficient. To obtain accurate data, the HDCC creep test must be performed beforehand when determining the creep coefficient in structural analysis.

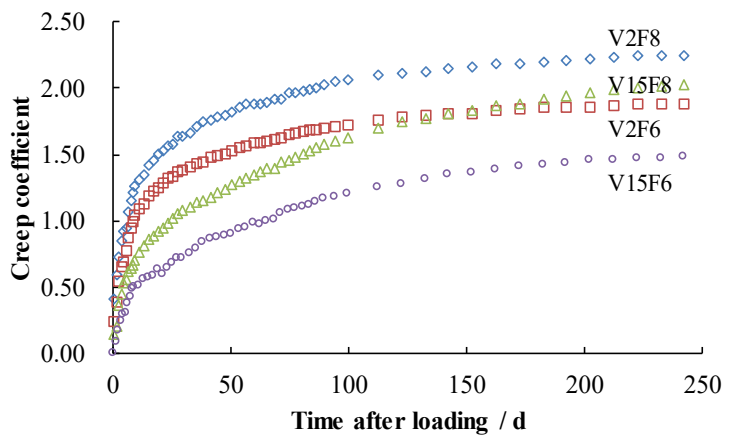

Figure 3. HDCC creep coefficient with loading at age of 7 days 


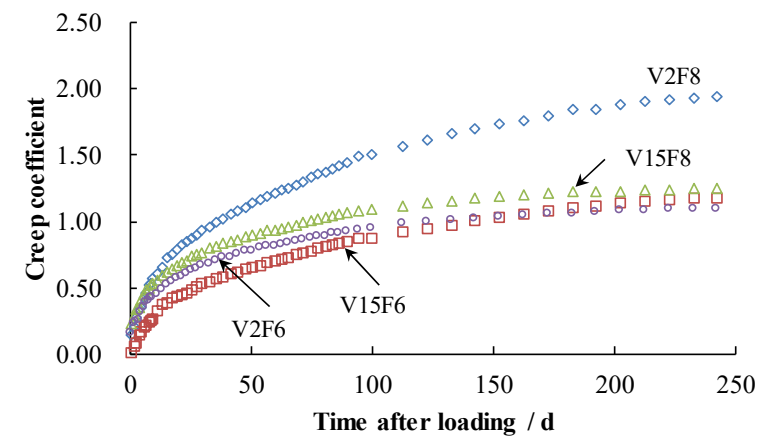

Figure 4. HDCC creep coefficient with loading at age of 28 days

\section{Conclusions}

The creep of HDCC is affected mainly by the content of PVA fiber and fly ash, and increases with increasing content of fiber and fly ash.

The amount of PVA fiber plays a leading role in the specific creep of HDCC under short-term load, and the amount of fly ash plays the key role under long-term load.

The time-history curve of HDCC creep coefficient is similar to that of specific creep. Furthermore, the specific creep and creep coefficient decrease significantly with increasing loading age.

The classical creep model described by a power exponential function is applicable to HDCC and can provide a mathematical calculation formula for structural design analysis and finite element calculation of HDCC.

\section{Acknowledgment}

This work was supported by the Natural Science Foundations of Jiangsu Province (Grants NO. BK20201125).

\section{References}

1. Li V C 2007 J. Journal of the Chinese ceramic society. 35(4):531-536.

2. Boshoff W P 2014 J. ACI Materials Journal. 111(5): 553-559.

3. Boshoff W P, Zijl G V 2007 J. Cement and Concrete Research. 37: 725-734.

4. Benny Suryanto, Koichi Maekawa and Kohei Nagai 2013 J. Journal of Advanced Concrete Technology. 11: $35-48$.

5. He Z H, Qian C X, Qian G F, et al 2010 J. Journal of Southeast University (Natural Science Edition). 40(S2):155-159.

6. Yu J C, Zhao Q X, Li Y H, et al 2013 J. Bulletin of the Chinese Ceramic Society. 32(9):1723-1728.

7. Rouse J M, Billington S L 2007 J. ACI Materials Journal. 104(2): 129-136.

8. Li K F, Yang C Q, Zhao Y B, et al $2020 \mathrm{~J}$. Construction and Building Materials. 230:1-9.
9. Zhang W M, Zheng Y Y, Yang C Q, et al 2018 J. Bulletin of the Chinese Ceramic Society. 37(09):2743-2747.

10. Wang Y Q, Liu X, Liu S G, et al 2020 J. Journal of Building Materials. 23(04): 823-830+845.

11. Sun L 2018 D. Hohhot: Inner Mongolia University of Technology.

12. Wang Y Q, Sun L, Liu S G, et al 2020 J. Acta Materiae Compositae Sinica. 37(1):205-213.

13. Zhang L H, Guo L P, Sun W, et al 2014 J. Journal of Southeast University (Natural Science Edition). 44(5): 1037-1040.

14. Zhu B F 1985 J. Journal of Hydraulic Engineering. (9): $54-61$.

15. Wang S, Li X Y 2010 J. Design of Hydroelectric Power Station. 26(4):79-81. 